\title{
A Call to Action: Promoting Diversity, Equity, and Inclusion in Parkinson's Research and Care
}

\author{
Bernadette Siddiqi* and Andrew Koemeter-Cox \\ The Michael J. Fox Foundation for Parkinson's Research, New York, NY, USA
}

Accepted 12 March 2021

Pre-press 3 April 2021

\begin{abstract}
The current base of knowledge around Parkinson's disease has been assembled in partnership with a cohort of participants that does not resemble the diversity of people with the disease. This poor representation in research results in an incomplete picture of the disease and disparities in care. The Michael J. Fox Foundation has defined four major areas of action: 1) identifying barriers and solutions to research participation; 2) funding inclusive research with greater participant diversity; 3) building a clinician/researcher workforce committed to health equity; and 4) supporting a more holistic understanding of PD. While factors driving disparities, including broader societal challenges, are complex, it is imperative that the PD research, care, and patient communities move in a decisive and coordinated fashion to identify and implement strategies that advance treatments for everyone with PD and eliminate care inequities.
\end{abstract}

Keywords: Health disparities, minority health, The Michael J. Fox Foundation, research diversity, health equity, Parkinson's research, clinical research, research participation, research Inclusivity, Parkinson's disease

Health disparities exist between many different groups and for a multitude of reasons [1]. Structural inequalities and systemic discrimination work with more proximal determinants of health leading to different incidences of disease, access to treatments, and outcomes for patients depending on their demographics $[1,2]$. Parkinson's disease (PD) is no exception, due to factors intrinsic and extrinsic to the research, drug development, and healthcare ecosystems [3]. To improve the lives of all people with PD, an aggressive strategy must be developed to address the extreme lack of representation that has thus far hampered research and care.

\footnotetext{
*Correspondence to: Bernadette Siddiqi, MA, The Michael J. Fox Foundation, $111 \mathrm{~W} 33^{\text {rd }}$ Street, 10th, Floor, New York, NY 10120, USA. Tel.: +1 212509 0995; E-mail: bsiddiqi@michael jfox.org.
}

PD affects nearly 1 million people in the U.S. and over 6 million worldwide, and those numbers are expected to rise considerably over the coming decades [4]. However, there is a real lack of definitive evidence on if, and how, the incidence, morbidity, or mortality from PD varies between socioeconomic or ethnic groups [5]. The current picture of PD has been assembled from a relatively homogenous population, and data remain sparse or are non-existent on many traditionally underrepresented groups: Black, Latino, Asian, Indigenous groups, LGBTQ+, and those of lower socioeconomic status [6]. Without these data, it is impossible to fully comprehend the breadth and depth of PD across the entire population.

Poor representation in research results in an incomplete picture of the true diversity of the disease. In the minority of PD clinical trials reporting race and ethnicity data, only $8 \%$ of participants were non-white [7]. An accurate reflection of the PD population in 
research is a critical challenge as genetic variation and other factors endemic to specific populations can greatly impact disease risk as well as effectiveness and metabolism of drugs [8-10]. From what little data are available, disparities in diagnosis and treatment exist for PD patients from certain underrepresented groups [11-14]. While not fully responsible, the lack of diversity in the research and care workforce are likely contributors to these disparities [15]. Evidence also indicates that presentation of the disease could differ across ethnicities, presenting complications for trial enrollment based on clinical diagnostic criteria $[5,16]$. Lack of information on different demographic groups has also hampered assessments of the full economic impact of the disease [17].

The Michael J. Fox Foundation (MJFF), the world's largest non-profit funder and strategic enabler of PD research and drug development, is committed to reducing health disparities and advancing treatments for everyone with PD. We have defined four major areas of action: 1) identifying barriers and solutions to research participation; 2) funding inclusive research with greater participant diversity; 3 ) building a clinician/researcher workforce committed to health equity; and 4) supporting a more holistic understanding of PD. While MJFF efforts in these areas are currently not sufficient to fully reduce health disparities in PD, our hope is that they will serve as solid starting points from which to learn and iterate expanded efforts.

For research cohorts to reflect the broader PD community requires reducing barriers to entry for participation and establishing inclusive practices. In 2018, MJFF funded the Fostering Inclusivity in Research Engagement for Underrepresented Populations in Parkinson's Disease (FIRE-UP PD) study. Led by Dr. Jonathan Jackson at the Community Access, Recruitment, and Engagement (CARE) Research Center at Massachusetts General Hospital, FIREUP PD found language, time, and the digital divide (no internet access or email) as common barriers to participation for underrepresented groups (Sanchez et al, manuscript in preparation). Conversely, community engagement and consistent, equitable offering of research opportunities to individuals (often found at sites with close integration of clinical care and research) resulted in increased participation from underrepresented groups [18]. The findings suggest that underrepresented populations are not asked or consistently engaged regarding PD research participation-a potential bias identified in other disease areas [19-21]. A second phase of FIRE-UP PD will further test and validate these initial findings, and MJFF will launch in late 2021 a program to train research staff at movement disorders centers on inclusive research practices. Including engagement, recruitment and retention strategies, the training will cover the importance of representation within the staff and partnerships with community organizations to engage underrepresented groups.

To put these learnings into more direct action, MJFF is piloting an effort within one of our core funding programs, the Therapeutic Pipeline Program (https://www.michaeljfox.org/funding-opportunities), for interventional trials to integrate inclusive practices toward normalizing greater diversity in trial participation. Applicants must explain how inclusive research practices will be implemented to recruit a diverse study cohort relative to the proposed research question and the site(s) catchment area. If a study will not aim for inclusivity and a diverse cohort, the applicant must provide scientific justification. Applicants are strongly advised to partner with community organizations to develop a study design and relevant engagement strategies. Research teams invited to the final application review stage may consult with our expert collaborators at the CARE Research Center to support their development of an inclusive study design and engagement, recruitment, and retention plan. Reviewers will provide feedback on applications, including the strength of diversity and inclusion in the proposed research. Studies that receive MJFF funding will regularly provide recruitment data to track progress, identify challenges, and receive additional support as needed.

To support a clinician-researcher workforce committed to inclusive research and health equity, MJFF has established fellowships that train the next generation of specialists in those practices. In 2020, Dr. Paris "AJ" Adkins-Jackson (https://www.massge neral.org/research/division-clinical-research/centers -units-and-faculty/care/paris-aj-adkins-jackson) at Massachusetts General Hospital was the first to receive the Fellowship for Advancing Diversity, Equity and Inclusion in Parkinson's Research supporting an early-career researcher pursuing research that serves marginalized PD communities. Her work will study the role of social determinants of health on research participation. MJFF hopes to increase its capacity to support more researchers in this area. In addition, The Edmond J. Safra Fellowship in Movement Disorders (https://www.michaeljfox.org/ edmond-j-safra-fellowship-movement-disorders) has funded, since 2014, training of 27 new movement 
disorder clinician-researchers. As of 2020, medical centers applying to this program are required to educate fellows on equitable access and inclusivity in their research and clinical care services. Lastly, MJFF is a "Collaborative Member" of the National Academies of Sciences' working group on Neuroscience Training (https://www.nationalacademies. org/our-work/action-collaborative-on-neurosciencetraining-developing-a-nimble-and-versatile-workfor ce), which has made a commitment to increasing diversity, equity and inclusion in the neuroscience workforce.

Toward our fourth area of action-building holistic disease understanding - the field must generate and support more research focused on increasing knowledge of PD in underrepresented groups. Genetics research has revolutionized disease understanding and therapeutic development for PD but has largely focused on European Caucasian populations. To understand the holistic genetic architecture of PD, the Aligning Science Across Parkinson's (ASAP) initiative, a coordinated research program to address key knowledge gaps in the basic mechanisms that contribute to Parkinson's development and progression, established the Global Parkinson's Genetic Program (GP2). Leveraging MJFF's grantmaking infrastructure and clinical coordination expertise, GP2 is an ambitious five-year program led by Dr. Andrew Singleton at the National Institute of Aging to genotype $>150,000$ volunteers worldwide. This expanded understanding of PD genetics will have wide implications for research and care benefiting the broad PD community.

Finally, in February 2021, MJFF launched a new funding opportunity: Promoting Diversity, Equity, and Inclusion in Parkinson's Research. Applicants were invited to submit proposals that focused on the study of incidence, etiology, and underlying pathology; diagnostic challenges; clinical presentation; healthcare behavior; health outcomes; and/or disease burden in underrepresented populations. Interdisciplinary teams were encouraged to apply, along with researchers from groups underrepresented in the scientific workforce. Proposals were submitted on April 21, 2021 and MJFF plans to make funding decisions in November 2021. To learn more about this program, visit www.michaeljfox.org/funding-opportunities.

Our understanding of the etiology, clinical presentation, and treatment of PD is growing, but remains far from complete. If preclinical and clinical PD research continues in its failure to represent all who have the disease, we will never develop a comprehen- sive understanding of the biological underpinnings of the disease, nor be ensured treatments will work for all people with PD. While factors driving these disparities, including broader societal challenges, are complex, it is imperative that the PD research, care, and patient communities move in a decisive and coordinated fashion to identify and implement strategies that can support the process of creating health equity in PD.

\section{ACKNOWLEDGMENTS}

The authors thank the following individuals for their contribution to this editorial and the work presented: Marco Baptista, PhD; Brett Benedetti, $\mathrm{PhD}$; Olivia Devine; Rachel Dolhun, MD; Jamie Eberling, PhD; Brian Fiske, PhD; Jessica Golden; Nadia Halim; Helen Hemley; Juliana Ison; Paris “AJ" Adkins-Jackson, PhD, MPH; Jonathan Jackson, $\mathrm{PhD}$; Julia Keefe; Catherine M. Kopil, PhD; Lauren McLaughlin; Maggie Kuhl; Joe Moran; Alyssa Reimer; Lindsey Riley; Angie Sanchez, MD; Todd Sherer, $\mathrm{PhD}$; and Andrew B. Singleton, $\mathrm{PhD}$ and the entire GP2 team.

\section{CONFLICT OF INTEREST}

The authors have no conflict of interest to report.

\section{REFERENCES}

[1] Wheeler SM, Bryant AS (2017) Racial and ethnic disparities in health and health care. Obstet Gynecol Clin North Am 44, $1-11$.

[2] Fiscella K, Sanders MR (2016) Racial and ethnic disparities in the quality of health care. Annu Rev Public Health 37, 375-394.

[3] Hemming JP, Gruber-Baldini AL, Anderson KE, Fishman PS, Reich SG, Weiner WJ, Shulman LM (2011) Racial and socioeconomic disparities in parkinsonism. Arch Neurol 68, 498-503.

[4] Dorsey ER, Elbaz A, Nichols E, Abd-Allah F, Abdelalim A, Adsuar JC, Ansha MG, Brayne C, Choi J-YJ, ColladoMateo D, Dahodwala N, Do HP, Edessa D, Endres M, Fereshtehnejad S-M, Foreman KJ, Gankpe FG, Gupta R, Hankey GJ, Hay SI, Hegazy MI, Hibstu DT, Kasaeian A, Khader Y, Khalil I, Khang Y-H, Kim YJ, Kokubo Y, Logroscino G, Massano J, Mohamed Ibrahim N, Mohammed MA, Mohammadi A, Moradi-Lakeh M, Naghavi M, Nguyen BT, Nirayo YL, Ogbo FA, Owolabi MO, Pereira DM, Postma MJ, Qorbani M, Rahman MA, Roba KT, Safari H, Safiri S, Satpathy M, Sawhney M, Shafieesabet A, Shiferaw MS, Smith M, Szoeke CEI, Tabarés-Seisdedos R, Truong NT, Ukwaja KN, Venketasubramanian N, Villafaina S, weldegwergs $\mathrm{Kg}$, Westerman R, Wijeratne T, Winkler AS, Xuan BT, Yonemoto N, Feigin VL, Vos T, Murray CJL (2018) 
Global, regional, and national burden of Parkinson's disease, 1990-2016: A systematic analysis for the Global Burden of Disease Study 2016. Lancet Neurol 17, 939-953.

[5] Bailey M, Anderson S, Hall DA (2020) Parkinson's disease in African Americans: A review of the current literature. $J$ Parkinsons Dis 10, 831-841.

[6] McInerney-Leo A, Gwinn-Hardy K, Nussbaum RL (2004) Prevalence of Parkinson's disease in populations of African ancestry: A review. J Natl Med Assoc 96, 974-979.

[7] Schneider MG, Swearingen CJ, Shulman LM, Ye J, Baumgarten M, Tilley BC (2009) Minority enrollment in Parkinson's disease clinical trials. Parkinsonism Relat Disord 15, 258-262.

[8] Arboleda-Velasquez JF, Lopera F, O'Hare M, DelgadoTirado S, Marino C, Chmielewska N, Saez-Torres KL, Amarnani D, Schultz AP, Sperling RA, Leyton-Cifuentes D, Chen K, Baena A, Aguillon D, Rios-Romenets S, Giraldo M, Guzman-Velez E, Norton DJ, Pardilla-Delgado E, Artola A, Sanchez JS, Acosta-Uribe J, Lalli M, Kosik KS, Huentelman MJ, Zetterberg H, Blennow K, Reiman RA, Luo J, Chen Y, Thiyyagura P, Su Y, Jun GR, Naymik M, Gai X, Bootwalla M, Ji J, Shen L, Miller JB, Kim LA, Tariot PN, Johnson KA, Reiman EM, Quiroz YT (2019) Resistance to autosomal dominant Alzheimer's disease in an APOE3 Christchurch homozygote: A case report. Nat Med 25, 1680-1683.

[9] Ortega VE, Meyers DA (2014) Pharmacogenetics: Implications of race and ethnicity on defining genetic profiles for personalized medicine. J Allergy Clin Immunol 133, 16-26.

[10] Nuytemans K, Rajabli F, Bussies PL, Celis K, Scott WK, Singer C, Luca CC, Vinuela A, Pericak-Vance MA, Vance JM (2020) Novel variants in LRRK2 and GBA identified in Latino Parkinson disease cohort enriched for Caribbean origin. Front Neurol 11, 573733.

[11] Chan AK, McGovern RA, Brown LT, Sheehy JP, Zacharia BE, Mikell CB, Bruce SS, Ford B, McKhann GM, 2nd (2014) Disparities in access to deep brain stimulation surgery for Parkinson disease: Interaction between African American race and Medicaid use. JAMA Neurol 71, 291299.
[12] Dahodwala N, Xie M, Noll E, Siderowf A, Mandell DS (2009) Treatment disparities in Parkinson's disease. Ann Neurol 66, 142-145.

[13] Dahodwala N, Siderowf A, Xie M, Noll E, Stern M, Mandell DS (2009) Racial differences in the diagnosis of Parkinson's disease. Mov Disord 24, 1200-1205.

[14] Flores LE, Verduzco-Gutierrez M, Molinares D, Silver JK (2020) Disparities in health care for Hispanic patients in physical medicine and rehabilitation in the United States: A narrative review. Am J Phys Med Rehabil 99, 338-347.

[15] Saleem S, Naveed S, Mohyud Din Chaudhary A, Zeshan M, Hafeez D, Siddiqi J, Khosa F (2020) Racial and gender disparities in neurology. Postgrad Med J, doi: 10.1136/postgradmedj-2020-138584

[16] Ben-Joseph A, Marshall CR, Lees AJ, Noyce AJ (2020) Ethnic variation in the manifestation of Parkinson's disease: A narrative review. J Parkinsons Dis 10, 31-45.

[17] Yang W, Hamilton JL, Kopil C, Beck JC, Tanner CM, Albin RL, Ray Dorsey E, Dahodwala N, Cintina I, Hogan P, Thompson T (2020) Current and projected future economic burden of Parkinson's disease in the U.S. NPJ Parkinsons Dis 6, 15.

[18] Jackson J, Sanchez A, Ison J, Hemley H, Siddiqi B (2020) Importance of diversity in Parkinson's research. Appl Clin Trials, pp. 13-15.

[19] Niranjan SJ, Martin MY, Fouad MN, Vickers SM, Wenzel JA, Cook ED, Konety BR, Durant RW (2020) Bias and stereotyping among research and clinical professionals: Perspectives on minority recruitment for oncology clinical trials. Cancer 126, 1958-1968.

[20] Hagiwara N, Penner LA, Gonzalez R, Eggly S, Dovidio JF, Gaertner SL, West T, Albrecht TL (2013) Racial attitudes, physician-patient talk time ratio, and adherence in racially discordant medical interactions. Soc Sci Med 87, 123-131.

[21] Cooper LA, Roter DL, Carson KA, Beach MC, Sabin JA, Greenwald AG, Inui TS (2012) The associations of clinicians' implicit attitudes about race with medical visit communication and patient ratings of interpersonal care. $\mathrm{Am}$ J Public Health 102, 979-987. 